\title{
Bathymetric LiDAR Green Channel Derived Reflectance: An Experiment from the Dongsha 2010 Mission
}

\author{
Wei-Tsun Lin ${ }^{1}$, Peter Tian-Yuan Shih ${ }^{1, *}$, Jie-Chung Chen ${ }^{2}$, and Chun-Jie Liao ${ }^{2}$ \\ ${ }^{1}$ Department of Civil Engineering, National Chiao Tung University, Hsinchu, Taiwan, R.O.C. \\ ${ }^{2}$ Department of Land Administration, Ministry of Interior, Taipei City, Taiwan, R.O.C.
}

Received 6 July 2015, revised 3 February 2016, accepted 19 February 2016

\begin{abstract}
Bathymetric LiDAR utilizes a green laser capable of penetrating water and surveying seafloor topography. The intensity of the echo identified as the seafloor carries information about the substrate type. However, besides the reflectance characteristics of the substrate, there are also other influencing factors, including those from the LiDAR system and the environment. The data collected in the 2010 Dongsha atoll bathymetric LiDAR mission is processed and analyzed in this study. The corrections for environmental factors, mainly contributed from the water column that is presented as the inherent optical parameters of water are retrieved from the recorded green laser waveform. Those from the system, such as deviations between the signal receptors or between laser beam angles to each interface, are eliminated with data from IMU (Inertial Measurement Unit), scanner controlling mechanisms, etc. The resulting reflectance from each flight line is compared in the overlap area. The reflectance of the west side strip is subtracted from that of the east side strip. The reflectance is scaled between zero and one. While the mean of the differences is -0.0037 , the standard deviation is 0.0436 for the flight line with a flight height of $400 \mathrm{~m}$. The mean and standard deviation are -0.0058 and 0.0272 , respectively, with flight height of $300 \mathrm{~m}$. When interpolating the reflectance from the $300 \mathrm{~m}$ flight altitude dataset into a surface after subtracting the point measurement from the $400 \mathrm{~m}$ flight altitude, the mean and standard deviations are -0.0215 and 0.0382 , respectively. This indicates that the consistency among flight lines of the same flight altitude is higher than those from different flight altitudes. A WorldView-2 (WV-2) image is compared with the LiDAR reflectance, and after atmospheric correction, the green band reflectance from WV-2 showed high similarities between the two image types. However, in the deep water region the one derived from LiDAR has much more information content.
\end{abstract}

Key words: Waveform, Reflectance, Attenuation coefficient, Backscatter coefficient

Citation: Lin, W. T., P. T. Y. Shih, J. C. Chen, and C. J. Liao, 2016: Bathymetric LiDAR green channel derived reflectance: An experiment from the Dongsha 2010 mission. Terr. Atmos. Ocean. Sci., 27, 565-576, doi: 10.3319/TAO.2016.02.19.02(ISRS)

\section{INTRODUCTION}

Airborne Bathymetric LiDAR (ABL) is a depth sounding technology that assembles GNSS (Global Navigation Satellite System), INS (Initial Navigation System), and laser scanning systems. The current design principle utilizes a green laser for sea floor reflection with optional support from other laser channels with different wavelengths for determining the sea surface characteristics. In comparison with shipborne sounding technology, ABL is featured with high efficiency and is particularly suitable for areas with navigational risks. The green laser beam channel waveforms contain several properties that permit the beam to travel through

\footnotetext{
* Corresponding author

E-mail: tyshih@mail.nctu.edu.tw
}

water. There are typically two stronger returns that correspond to the water surface and sea bottom. The time difference between these two returns provides information for the travel slant range in water. The water depth and seafloor topography are obtained with IMU (Inertial Measurement Unit) and other data (Guenther 1985). The roughness, slope, curvature and bathymetric position index (BPI), and other indices are then computed. Seafloor topography provides valuable information for coral reef monitoring (Brock et al. 2006; Wedding et al. 2008) and habitat mapping (Lundblad et al. 2006; Wilson et al. 2007).

The bottom return amplitude in the waveform is influenced by the seafloor illuminated area condition, which is related to the substrate type. After removing influences 
from other factors, the spot reflectance could be derived to provide further information for habitat mapping (Chust et al. 2010; Micallef et al. 2012). Besides reflectance, other waveform features such as skewness, kurtosis, pulse width and pulse area, could also be useful for characterizing the substrate type (Cottin et al. 2009; Collin et al. 2011, 2012; Tulldahl and Wikström 2012).

Although the bottom return amplitude is largely related to the reflectance, there are other factors that affect the waveform shape or cause biases. Directly taking the amplitude as the reflectance would impose large errors upon the data. Based on the source, these factors could be categorized into two types. The first are those caused by the LiDAR system status. The other type results from the environmental condition of the air, water, interface, and seafloor. Factors related to the LiDAR system, such as deviations between the signal receptors and interface angles, are eliminated with data from IMU, scanner-controlling mechanisms, and other information sources. Some are geometric, such as the sensor altitudes and scanner angles. These could be resolved with underlying geometric constraint whereas factors related to the environmental condition could be retrieved by the waveform. The waveform portion between the surface and bottom return is composed mainly of back scatter from hydrosols within the water column. The envelope shows the energy decays with increasing depth and can be used to retrieve inherent optical water characteristics (Billard and Wilsen 1986). Phillips et al. (1984) assessed the derivation of optical properties from $\mathrm{ABL}$ waveforms with in situ measurement. Billard et al. (1986) and Hoge et al. (1988) implemented the retrieval algorithm for several case studies.

Besides the two broad system and environment categories, water surface condition and seafloor topography also contribute to the amplitude (Wang and Philpot 2007). The former includes the water surface wave. The latter includes the slope and aspect which causes changes in the incident angle from different viewing orientations and stretches the bottom return (Steinvall et al. 1994; Steinvall and Koppari 1996; Tulldahl and Steinvall 2004).

Both the systematic and environmental factors are considered in reflectance retrieval. The systematic factors include laser receiver gain, flight deviation, and the scanner angle. Environmental error compensation focuses on the water optical properties effect. The resulting reflectance from each flight line is compared with each other in the overlap area for assessment. The reflectance from an optical satellite image in the green band is also included for comparison.

\section{EXPERIMENTAL DATA}

The datasets collected in the 2010 Dongsha atoll bathymetric LiDAR mission are used in this study. The survey was conducted with AHAB HawkEye II bathymetric LiDAR system in September of 2010 (Shih et al. 2011). This system has four receiving channels, including two green channels, one infrared channel and one Raman scatter channel. The HawkEye II system acquires $4 \mathrm{kHz}$ bathymetric and $64 \mathrm{kHz}$ topographic LiDAR soundings simultaneously. The off nadir angle of the laser beam is maintained at approximately at $20^{\circ}$. For each LiDAR sounding, the waveforms of four channels are recorded for post processing and further analysis. Infra-red and Raman scattering channel waveforms contain information near the water surface and are mainly used to determine the surface position. Our work in this study focuses on processing green channel waveforms. An IDE UI-2250SE digital camera with $1200 \times 1600$ pixel resolution is used for taking photographs for the LiDAR scanned area at $1 \mathrm{~Hz}$ (Henrik 2006).

The study site is Dongsha atoll, which is located about $480 \mathrm{~km}$ southwest of Taiwan. The shape of Dongsha atoll is approximately a ring. Within the Dongsha atoll, numerous submerged coral reefs are scattered. Dongsha Island is the only land above water all year round. In the Dongsha 2010 mission $400 \mathrm{~m}$ flight altitude survey covered the whole Dongsha atoll. The point density of the dataset is one point per $3.5 \times 3.5 \mathrm{~m}$. Another $2 \times 2 \mathrm{~m}$ point density survey with $300 \mathrm{~m}$ flight altitude covered the east portion of Dongsha atoll. The survey flight lines are shown in Fig. 1. Flight lines were designed in a north-south direction to minimize the sun glint effect. The survey parameters for the two datasets are listed in Table 1.

\section{DATA PROCESSING}

The reflectance derivation flowchart is shown in Fig. 2. The bottom return amplitude is extracted from the green channel waveform. The systematic bias and environmental errors are corrected in a follow up process. Further calibration for the dataset is needed to minimize the deviation in the overlap of adjacent flight lines. This chapter describes how to correct these errors with a universal calibration model for the whole dataset. The deriving reflectance procedure for each part is as follows.

\subsection{Systematic Bias Correction}

The correction for the individual point systematic bias includes laser receiver gain, flight deviation, and the scanner angle. In the HawkEye II system, the received laser power signal from the two green channel receivers is applied with a TVG (time-varied gain) filter to enhance the bottom return (red line in Fig. 3). The applied TVG curve for each individual point was recorded along with the corresponding green channel waveform. Therefore, the gain offset bias could be compensated according to the applied TVG curve. Flight deviation and the scanner angle bias are caused by flight attitude (row/pitch/yaw) inconsistency and laser beams off nadir angle. These two factors would cause the incident 


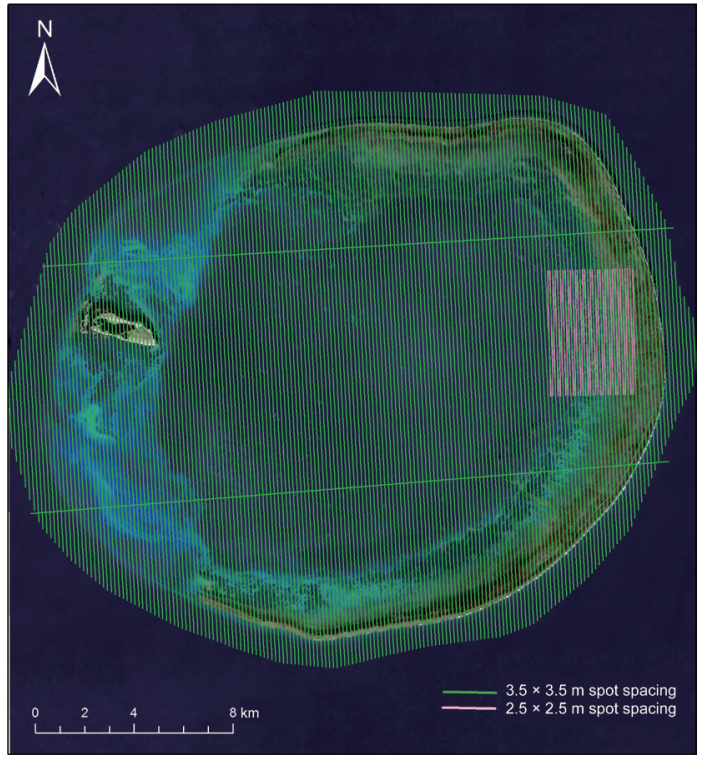

Table 1. Survey parameters of 2010 Dongsha atoll bathymetric LiDAR mission.

\begin{tabular}{c|cc}
\hline Point spacing (m) & $3.5 \times 3.5$ & $2 \times 2$ \\
Flight altitude (m) & 400 & 300 \\
Flight speed (kn) & 150 & 150 \\
Swath width (m) & 160 & 120 \\
Cover area $\left(\mathbf{k m}^{2}\right)$ & 506 & 20 \\
Total flight lines & 183 & 26 \\
\hline
\end{tabular}

Fig. 1. The flight lines in 2010 Dongsha atoll bathymetric LiDAR mission (Green: $3.5 \times 3.5 \mathrm{~m}$; Purple: $2 \times 2 \mathrm{~m}$ ). (Color online only)

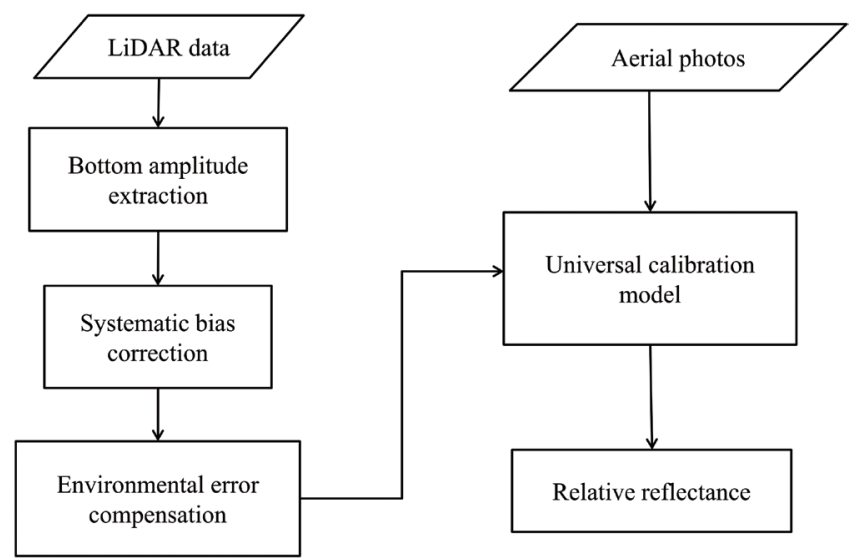

Fig. 2. Flowchart of reflectance retrieval.

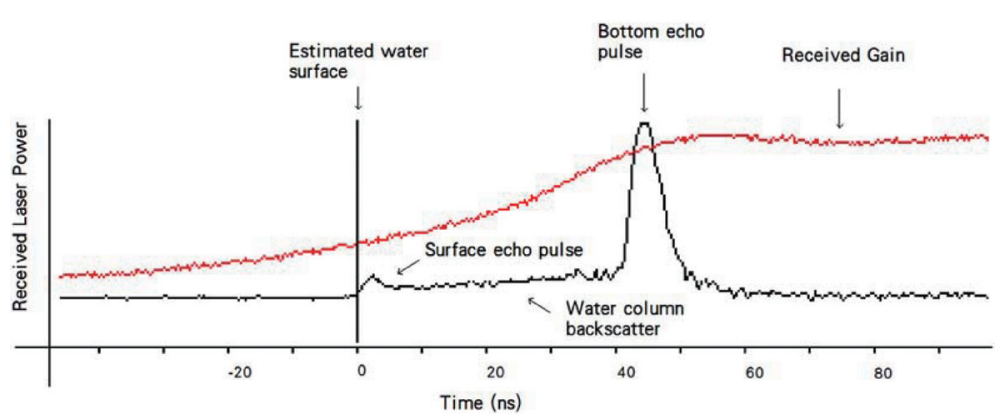

Fig. 3. The gained return waveform of green channel (Liu et al. 2010). (Color online only) 
angle to be different between pulses. The compensation for these two bias factors could be applied based on the IMU system records and scanner controller (Liu et al. 2010).

\subsection{Environmental Error Compensation}

The inherent optical properties of water need to be considered regarding environmental errors. As a photon travels through water it interacts with the water molecules and suspended particulate matter. These interactions weaken the laser beam. Therefore, the properties of the water through which the laser passes through need to be considered in the retrieving reflectance process. Billard et al. (1986) stated that the inherent optical properties relevant for monochromatic un-polarized light are absorption coefficient, scattering coefficient, and volume scattering function. As the emitted laser pulse energy $P_{0}$ is emitted from the aircraft at flying altitude $H$ into water with refractive index $n$, the energy returns to the receiver with area $A$ can be modelled with a simplified radiative transfer equation (Gordon 1982):

$\frac{d P(r)}{d r}=\frac{T^{2} A P_{0} \beta(\pi) \exp (-2 k r)}{n^{2}(H+r)^{2}}$

where $T$ is the Fresnel transmittance of interface, $r$ is the distance the laser beam travels in the water, $\beta(\pi)$ is the volume scattering function, and $k$ is the attenuation coefficient. If we assume that the water column the laser beam travels through is uniformly mixed, the $\beta(\pi)$ and $k$ are independent of $r$. Therefore, the simplified radiative transfer equation in Eq. (1) can be further simplified to exponential form:

$P(r)=B \exp (-2 k r)$

Where $B$ is the backscatter parameter, which is a combination of $\beta(\pi)$ and other variables in Eq. (1). The power returned to the receiver decreases with an exponential function for backscattering parameter, attenuation coefficient, and the distance that the laser travelled in the water $r$. According to the exponential form of Eq. (2), the backscattering parameter and attenuation coefficient could be estimated with regression analysis on the backscatter envelope logarithm portion of the waveform. However, the simplified Eq. (2) is based on the uniform mixing assumption within the water column travelled through by each laser pulse. Fitting exponential decay into the waveforms might be inappropriate in some cases, such as those pulses traveling in non-uniform water columns. Therefore, the alternative method should be employed. In this study, the non-uniform mixing water attenuation developed from atmospheric LiDAR work is used. Billard et al. (1986) and Hoge et al. (1988) support the feasibility of the method to adapt to the non-uniform water cases. The backscattering parameter $B$ and attenuation coef- ficient $k$ relationship can be approximated in a power law form (Klett 1981):

$B=$ const $k^{c}$

Where $c$ is the constant dependent on the laser pulse wavelength and the water properties. In atmospheric LiDAR work, the reported value $c$ generally ranges from $0.67-1$. In this study for bathymetry, $c$ is taken as 1 . The non-uniform water column attenuation case $k(r)$ can be presented as a function Eq. (4), which describes the backward integration of traveling distance $r$ :

$k(r)=\frac{\exp \left\{\left[P(r)-P\left(r_{m}\right)\right] / c\right\}}{\frac{1}{k_{m}}+\left(\frac{2}{c}\right) \int_{r}^{r_{m}} \exp \left\{\left[P\left(r^{\prime}\right)-P\left(r_{m}\right)\right] / r^{\prime}\right\} d r^{\prime}}$

Where $r_{m}$ is the point with small received energy $P\left(r_{m}\right)$ before bottom return in the waveform, and $k_{m}$ is an initial attenuation coefficient value at $r_{m}$. As the $r$ decreased from $r_{m}$, the $k(r)$ is determined by the ratio of the two numbers, which are both gradually increased. This form is stable numerically and insensitive to the selected $r_{m}$ (Billard et al. 1986). With Eqs. (3) and (4), the backscattering parameter and attenuation coefficient of non-uniform mixing water for each laser pulse can be estimated with regression analysis. The regression analysis was achieved with non-linear least squares by minimizing $S$ in Eq. (5):

$S=\sum_{r=1}^{r_{m}}\left[P(r)-f\left(r, B_{r}, k_{r}\right)\right]^{2}$

Backscattering parameter and attenuation coefficient extraction is achieved in this study using CSS (Coastal Survey Studio) software (Isaksson 2009), which is the post-processing software of the HawkEye II system. These extracted water parameters are then applied in the environmental error compensation procedure.

\subsection{Universal Calibration Model}

In environmental error compensation each flight line is segmented into blocks. Regression analysis is then performed on these blocks. The local inherent optical properties are estimated separately for each block. Therefore, the water column attenuation effect can be compensated for each laser pulse in the block, whereas the discrepancy between flight lines still exists. A universal calibration method is applied to the entire dataset. The universal calibration model is constructed with training samples which provide references from relatively high reflectance. These relatively high reflectance samples are therefore the reference value of 
relatively high reflectance with different depth ranges in the process. The selected training samples should be the bright geological material, for example, white sand or bright rock, etc. The water depth range for these samples should be extended as far as possible.

In the process of creating a calibration model 12 areas of high reflectance are selected with information from aerial photos captured simultaneously by the digital camera. Figure 4 shows the interface for selecting the training samples. The area of interest is selected from the complete dataset overview (Fig. 4a) with a box. The elevation, Fig. 4b, and reflectance, Fig. 4c, are then displayed in separate windows for further elaborating upon the training sample. The aerial image of the training sample is then displayed, Fig. $4 d$, to verify the selection.

Description of 12 selected sample areas are listed in Table 2. The water depth ranges from approximately $0-8.5 \mathrm{~m}$. The distribution is shown in Fig. 5 and corresponding images in Fig. 6. The samples with high reflectance that can be distinguished from the photos are located at the left portion of the Dongsha atoll. The high reflectance areas with nearly zero depth could only be found surrounding Dongsha Island, which is located at the west part of Dongsha atoll. Given this spatial constraint, the universal model based on the 12 training samples is applied to both the 300 and $400 \mathrm{~m}$ flight altitude datasets, even though none of the training samples are located in the area covered by the $300 \mathrm{~m}$ flight altitude.

\subsection{Relative Reflectance}

After the calibration process the corrected amplitude is then normalized into 0 - 1 and named as relative reflectance. For each point, its relative reflectance is the ratio between the reflectance of individual point and the highest reflectance in the whole dataset.

\section{RESULTS AND DISCUSSION}

The calibration process improvement can be identified both visually and quantitatively. The raw reflectance, which is the rescaled amplitude, is shown in Fig. 7. The calibrated data is shown in Fig. 8. Significant improvement is observed from both the 300 and $400 \mathrm{~m}$ flight altitude datasets. The $300 \mathrm{~m}$ dataset is shown in the enlarged version to the right of the figures. Many more features are revealed in the calibrated dataset. The quantitative experiment assessment includes three parts: (1) The discrepancy between flight lines at the same flying height. There are two datasets with different flight altitudes in this category and evaluated separately. (2) The discrepancy between datasets of different flying heights. (3) The comparison of reflectance derived from different sensors, which are bathymetric LiDAR and WorldView-2 (WV-2) satellite image.

\subsection{Differences Between Flight Lines with Same Flying Height}

The quantitative assessment is realized by evaluating the differences between the overlap areas. For each pair of overlap strips, the reflectance of the west side strip is interpolated into the surface and then subtracted from each point in the eastside strip. Table 3 shows the related statistics. Improvement can be observed from the reduced standard deviations in both datasets. For the $400 \mathrm{~m}$ flight altitude dataset the overall standard deviation of reflectance differences is significantly decreased from 0.1308 to 0.0436 . The $300 \mathrm{~m}$ flight altitude dataset, which completed all the flight lines in one day, already has smaller standard deviation before calibration. The results still show improvement. Deviation improved from 0.0464 to 0.0272 . The bias represented by the mean does not change much in both datasets. Although all of the biases increased slightly after the calibration, the values are not significant.

While examining the relationship between reflectance difference and water depth, shallow water exhibits a larger deviation. As shown in Fig. 9 the scatter plot of one flight line pair, reflectance in the deep water region has a smaller deviation. An interesting feature is observed from Fig. 10, the spatial distribution of points. That is, points with larger reflectance deviation are colored in red and blue. Most of these points are located at the places nearing the coral patch. The higher density blue points along the edge of the coral patch can be observed. This may result from the terrain slope which changes the incidence angle from the two sides, and was not modelled in the CSS processing software.

\subsection{Comparison of Datasets with Different Flying Height}

To compare datasets with different flight altitudes, the whole $300 \mathrm{~m}$ flight altitude dataset was interpolated into a surface. The differences between the surface and each overlapping point in the $400 \mathrm{~m}$ flight altitude dataset are calculated. The overall standard deviation of differences is also significantly reduced, changed from 0.0791 to 0.0382 , whereas the bias changed from -0.0021 to -0.0215 , a relatively larger value.

\subsection{Comparison Between Bathymetric LiDAR and WV-2 Satellite Image}

The optical satellite image reflectance and water optical properties were applied for water depth retrieval (Lyzenga 1981; Stumpf et al. 2003; Bramante et al. 2013). Although the limitation of workable depth and requirement for water clarity is relatively higher, satellite images have the advantage of being able to provide multispectral information on large areas within a short time. The reflectance derived 
from the green channel of WV-2 image is used for comparison in this study. The image, 052901328070_01_P002, was acquired in October 2013 and covers the east portion of Dongsha atoll. The retrieved reflectance range is rescaled to 0 and 1 (Fig. 11). The time difference between the airborne LiDAR, September 2010, and the WV-2 image is about 3 years. During this period the seabed may have changed. Moreover, the acquisition season for the two datasets is also different. Although they are only one month apart, it is in the transition zone of the two dominant weather systems, southwest flow and northwest trades. Seasonal variations in the water column such as current and tide would affect the depth and water optical properties and therefore influence the retrieved reflectance. Although time differences between two datasets may influence the reflectance, the trend should be approximately consistent.

Table 4 shows the statistics of reflectance differences between ABL and the green band of WV-2 categorized by (a)

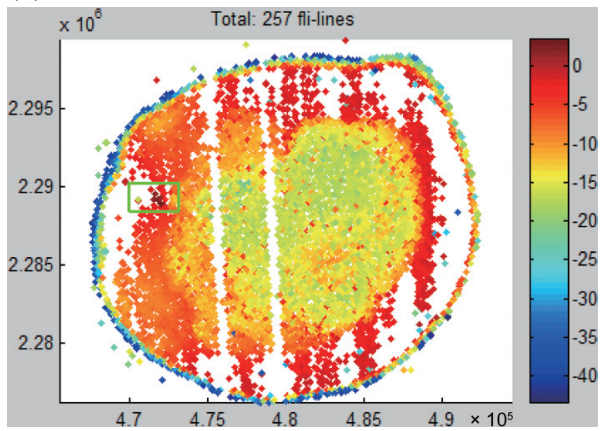

(c)

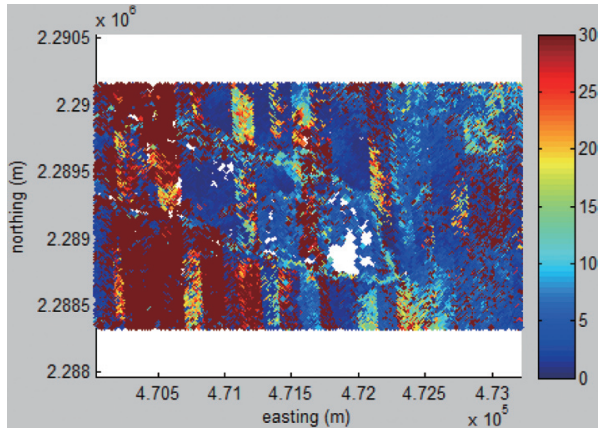

(b)

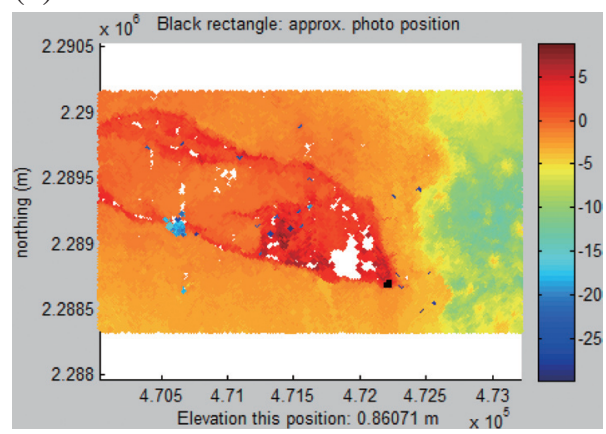

(d)

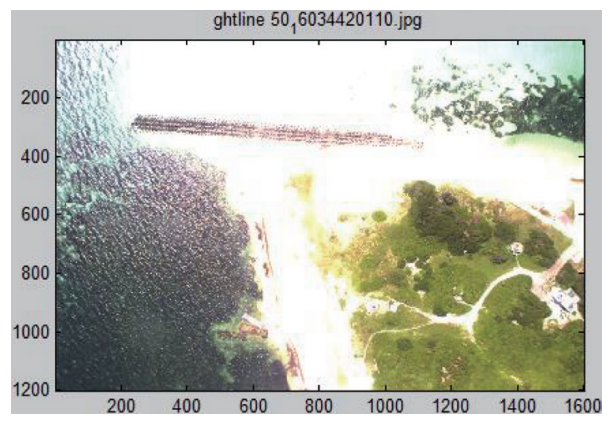

Fig 4. The interface of training sample selection. (a) The overview of dataset and interested area selection; (b) and (c) detail of elevation and reflectance in interested area; (d) corresponding photos of training sample. (Color online only)

Table 2. The description of training areas.

\begin{tabular}{cccc}
\hline Area & pts & Approximate Depth (m) & Position \\
\hline 1 & 224 & 0 & East part of island \\
2 & 246 & 0 & Southeast part of island \\
3 & 405 & 0 & South part of island \\
4 & 589 & 7 & South of island \\
5 & 363 & 7 & South of island \\
6 & 454 & 4.5 & South of island \\
7 & 1202 & 6.6 & North of island \\
8 & 495 & 8.3 & South of island \\
9 & 158 & 8.5 & South of island \\
10 & 731 & 5.5 & North of island \\
11 & 525 & 4 & South of island \\
12 & 877 & 2.5 & East of island \\
\hline
\end{tabular}




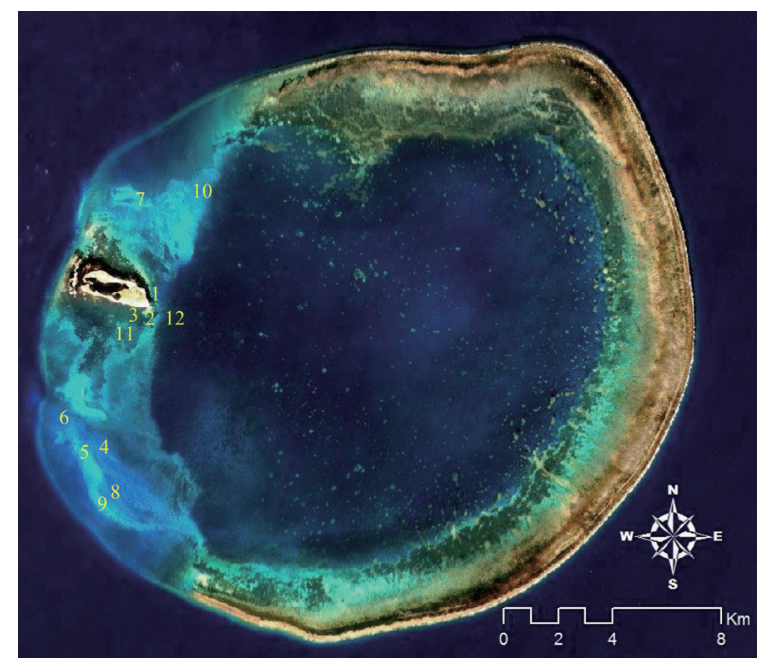

Fig. 5. Distribution of training areas. (Color online only)

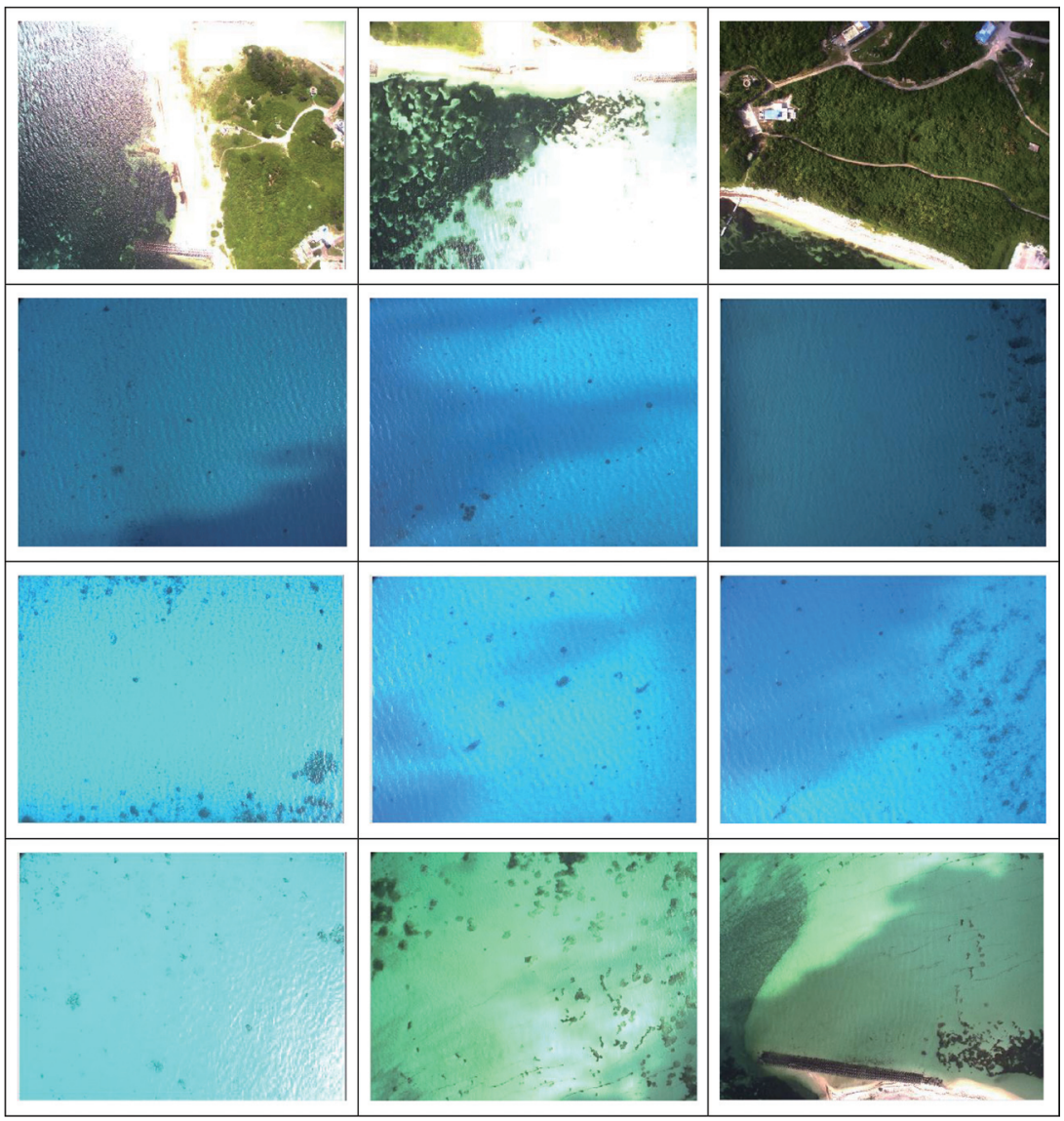

Fig. 6. The corresponding aerial photo of selected training samples. (Color online only) 


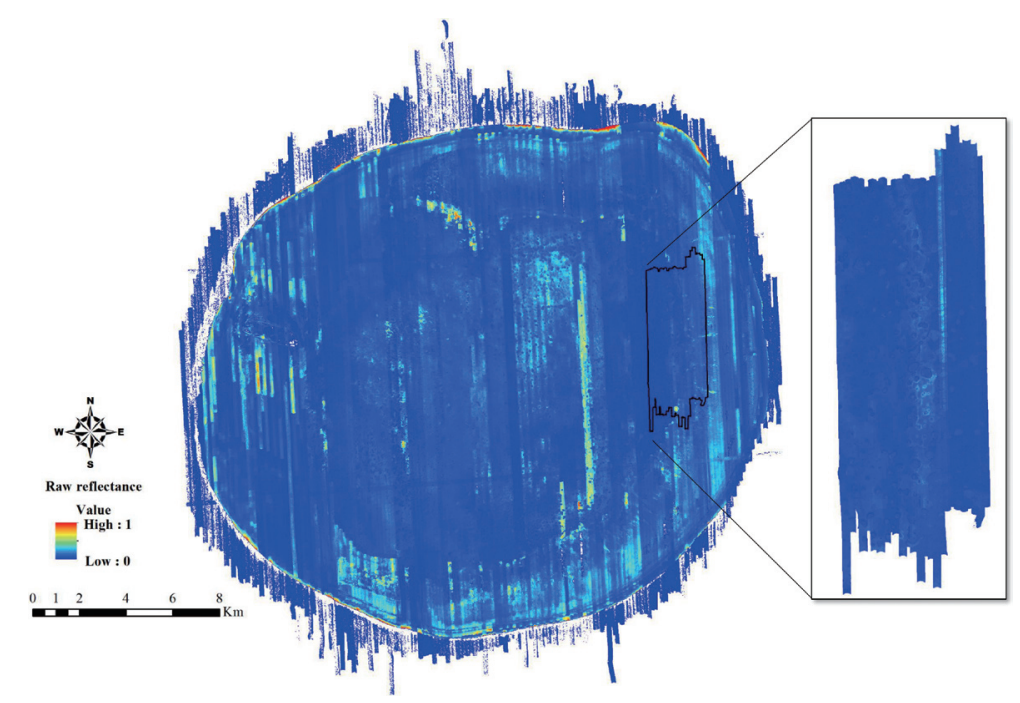

Fig. 7. Visual results of raw reflectance. (Color online only)

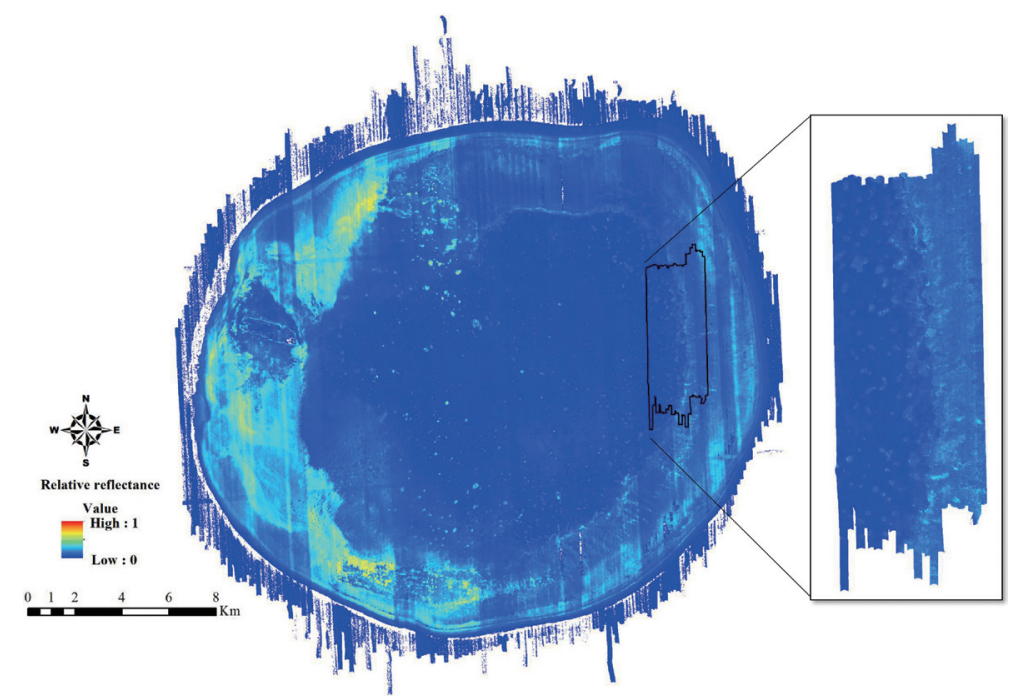

Fig. 8. Visual results of calibrated relative reflectance. (Color online only)

Table 3. The statistics of reflectance difference.

\begin{tabular}{c|c|c|c}
\hline \multirow{2}{*}{ Statistics of differences } & \multicolumn{2}{c}{ Flying height } \\
\cline { 3 - 4 } \multicolumn{2}{|c}{ Before calibration } & $\mathbf{4 0 0} \mathbf{~ m}$ & $\mathbf{3 0 0} \mathbf{~ m}$ \\
\hline & Mean & -0.0028 & -0.0022 \\
\cline { 2 - 4 } & Standard deviation & 0.1308 & 0.0464 \\
\hline \multirow{2}{*}{ After calibration } & Mean & -0.0037 & -0.0058 \\
\cline { 2 - 4 } & Standard deviation & 0.0436 & 0.0272 \\
\hline
\end{tabular}




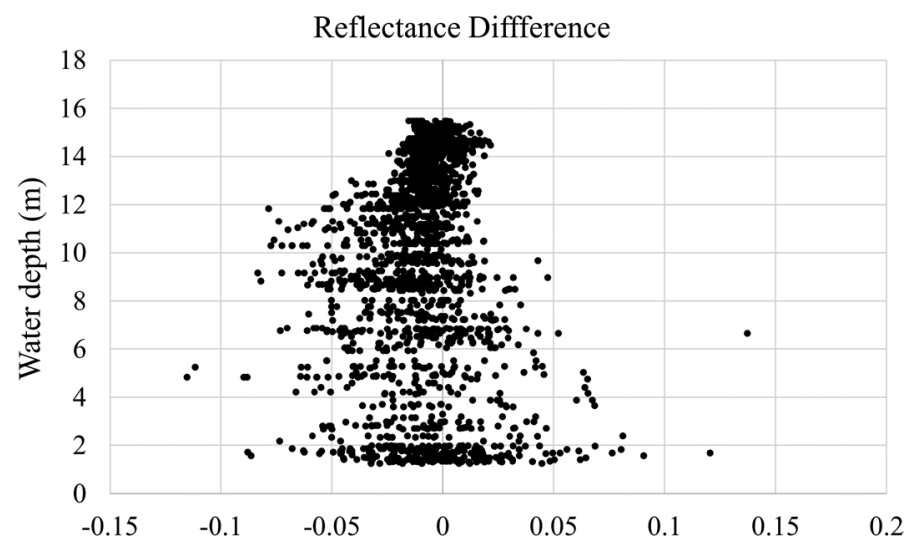

Fig. 9. Relationship between reflectance difference and the elevation.
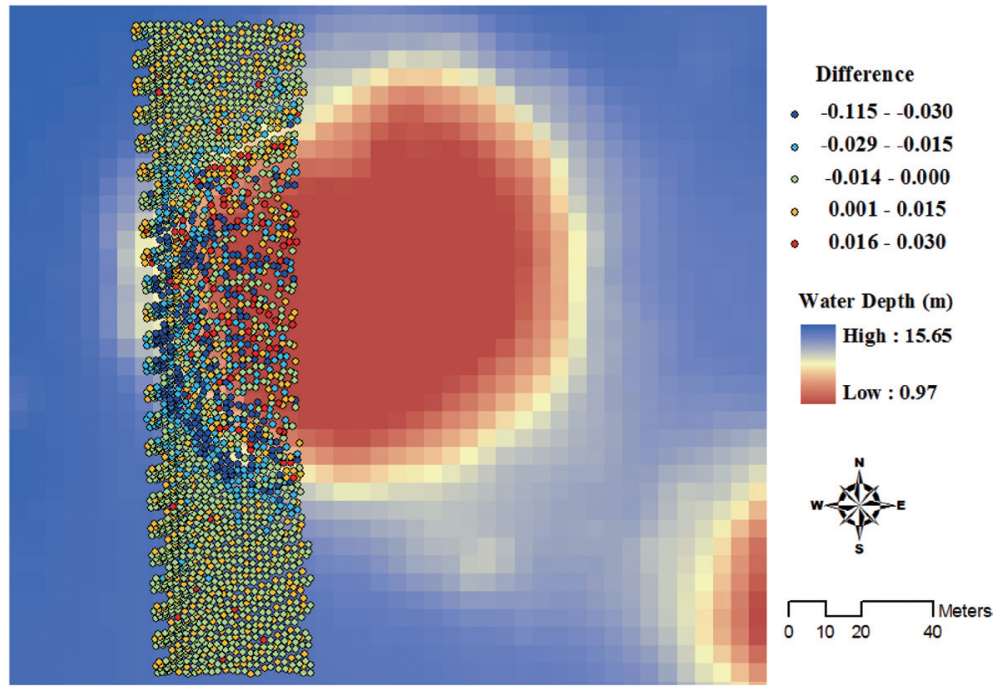

Fig. 10. Distribution of reflectance differences related to elevation. (Color online only)

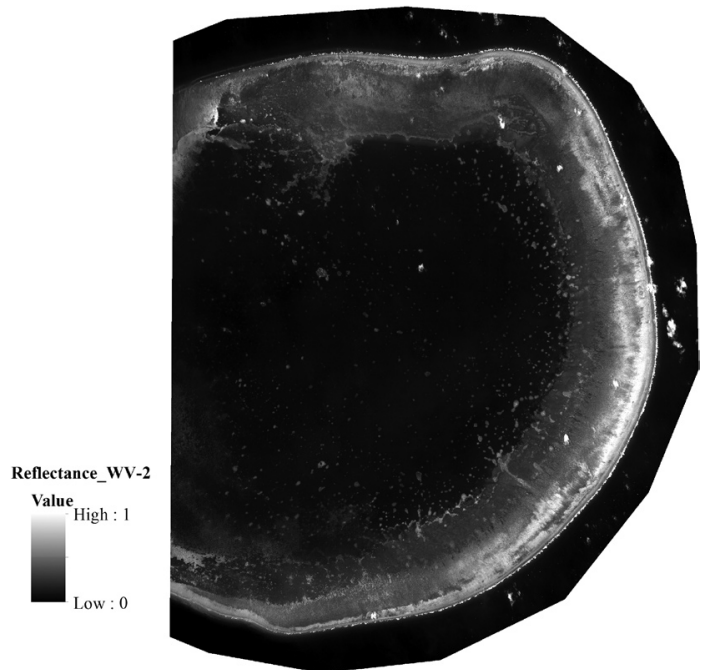

Table 4. The statistic of reflectance differences with respect to depth class.

\begin{tabular}{ccc}
\hline Range of depth (m) & Mean & Standard deviation \\
\hline $0-5$ & -0.15 & 0.12 \\
$5-10$ & -0.07 & 0.07 \\
$10-15$ & -0.11 & 0.03 \\
$15-20$ & -0.12 & 0.01 \\
$20-25$ & -0.11 & 0.03 \\
$25-30$ & -0.12 & 0.03 \\
$>30$ & -0.12 & 0.04 \\
\hline
\end{tabular}

Fig. 11. Reflectance derived from the green channel of WV-2 image. 
water depth. As the reflectance derived from WV-2 is subtracted from LiDAR results, the mean of the differences are negative in all classes. The most significant deviation occurs in the class of water depth $0-5 \mathrm{~m}$. Geographically, most of these areas are in the white water zone along the edge of the reef crest. This phenomenon indicates that the steep terrain condition might significantly affect the reflectance retrieval from optical satellite images.

An approximately $6 \mathrm{~km}$ long profile is taken from a flight line. The reflectance and water depth along this profile are shown in Fig. 12. The fluctuating tendency of the results derived from different sensors are similar. Although the original reflectance of WV-2 (green line) approaches 0.1 at the position with a depth larger than about $10 \mathrm{~m}$ (black line), the rescaled WV-2 reflectance (red line) shows high consistency with bathymetric LiDAR (blue line).

\section{CONCLUSION}

This study evaluated the performance of the reflectance retrieval process. Both systematic and environmental factors were considered. In the consistency between flight lines evaluation, two datasets show significant improvement in overlapping areas according to the reduced standard deviation of differences. In comparing datasets with different flight altitudes, the discrepancy is also reduced, whereas the bias between datasets is enlarged after the calibration. The bias might be caused by the sampling limitation in the construction of universal calibration models. Only datasets at $400 \mathrm{~m}$ flight altitude were used for sampling due to their relatively larger coverage and increased amount of targets with high reflectance. The resulting model was applied to $300 \mathrm{~m}$ dataset calibration. The magnitude of difference was also found to be depth dependent. Shallow water exhibits larger deviations. For spatial distribution, the terrain slope is likely to be the main influencing factor. This indicates that the modelling of influence from terrain slope to the incidence angle should be included in the calibration.

Compared with the reflectance derived from the green channel of WV-2 image, bathymetric LiDAR shows better capability to delineate the bottom features, especially for places with water depth larger than $10 \mathrm{~m}$. After rescaling, reflectance derived from the green channel of WV-2 shows high consistency with the one from bathymetric LiDAR. The rescaled reflectance of WV-2 shows generally higher values than LiDAR. The highest mean and standard deviation of differences were both for the water depth category from $0-5 \mathrm{~m}$. The training areas in this study were selected with the aid of aerial photos. While ground truth and other map resources could be helpful in improving the quality of the calibration model, these materials were unavailable at the time of this study.

While ABL provides an essential surveying tool for bathymetric mapping, the waveforms also provide information on both the water column and sea floor substrate. The retrieved laser reflectance carries a description of the seafloor coverage type and could be applied to substrate classification.

Acknowledgements The authors are deeply indebted to the Coast Guard Administration, particularly Dongsha Headquarters, Marine National Park Headquarters, Air Force and Civilian Aviation Authority of the Taiwan Government, Daily Air, and many others. Without their generous support this mission would have been impossible. The authors also wish to express their sincere gratitude to Mr. Dushan Arumugam, Miss Almudena Perez-Gonzalez, Mr. Jonas Gunnarsson, and Mr. Sean Maguire for their great contributions

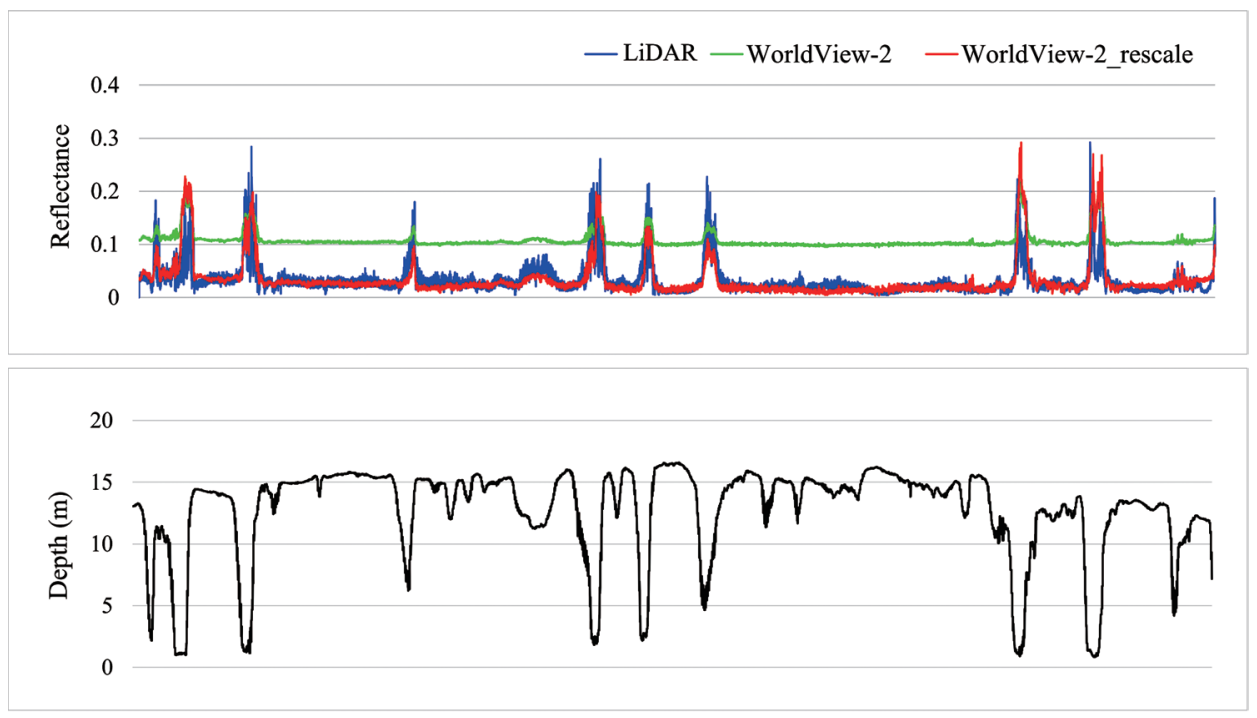

Fig. 12. Reflectance and water depth along a profile. (Color online only) 
to the survey, and Dr. Kenny Johansson for the reflectivity processing. The constructive comments and suggestions from the two Anonymous Referees are gratefully acknowledged, which greatly improved the readability of this article. In the long process of this research, a part of funding to the first two authors was received from Ministry of Science and Technology, grant number MOST 104-2119-M-009-011.

\section{REFERENCES}

Billard, B. and P. J. Wilsen, 1986: Sea surface and depth detection in the WRELADS airborne depth sounder. Appl. Optics, 25, 2059-2066, doi: 10.1364/AO.25.002059. [Link]

Billard, B., R. H. Abbot, and M. F. Penny, 1986: Airborne estimation of sea turbidity parameters from the WRELADS laser airborne depth sounder. Appl.Optics, 25, 2080-2088, doi: 10.1364/AO.25.002080. [Link]

Bramante, J. F., D. K. Raju, and T. M. Sin, 2013: Multispectral derivation of bathymetry in Singapore's shallow, turbid waters. Int. J. Remote Sens., 34, 2070-2088, doi: 10.1080/01431161.2012.734934. [Link]

Brock, J. C., C. W. Wright, I. B. Kuffner, R. Hernandez, and P. Thompson, 2006: Airborne lidar sensing of massive stony coral colonies on patch reefs in the northern Florida reef tract. Remote Sens. Environ., 104, 31-42, doi: 10.1016/j.rse.2006.04.017. [Link]

Chust, G., M. Grande, I. Galparsoro, A. Uriarte, and Á. Borja, 2010: Capabilities of the bathymetric Hawk Eye LiDAR for coastal habitat mapping: A case study within a Basque estuary. Estuar. Coast. Shelf Sci., 89, 200-213, doi: 10.1016/j.ecss.2010.07.002. [Link]

Collin, A., B. Long, and P. Archambault, 2011: Benthic classifications using bathymetric LIDAR waveforms and integration of local spatial statistics and textural features. J. Coast.Res., 62, 86-98, doi: 10.2112/SI_62_9. [Link]

Collin, A., B. Long, and P. Archambault, 2012: Merging land-marine realms: Spatial patterns of seamless coastal habitats using a multispectral LiDAR. Remote Sens. Environ., 123, 390-399, doi: 10.1016/j. rse.2012.03.015. [Link]

Cottin, A. G., D. L. Forbes, and B. F. Long, 2009: Shallow seabed mapping and classification using waveform analysis and bathymetry from SHOALS lidar data. Can. J. Rem. Sens., 35, 422-434, doi: 10.5589/m09036. [Link]

Gordon, H. R., 1982: Interpretation of airborne oceanic lidar: Effects of multiple scattering. Appl. Optics, 21, 2996-3001, doi: 10.1364/AO.21.002996. [Link]

Guenther, G. C., 1985: Airborne laser hydrography: System design and performance factors. NOAA Professional Paper Series, National Ocean Service 1, 385 pp.

Henrik, K., 2006: HawkEye II Technical Description, Airborne Hydrography AB.
Hoge, F. E., C. W. Wright, W. B. Krabill, R. R. Buntzen, G. D. Gilbert, R. N. Swift, J. K. Yungel, and R. E. Berry, 1988: Airborne lidar detection of subsurface oceanic scattering layers. Appl. Optics, 27, 3969-3977, doi: 10.1364/AO.27.003969. [Link]

Isaksson, A., 2009: Coastal Survey Studio Mark II Manual Version 2.X, Airborne Hydrography AB.

Klett, J. D., 1981: Stable analytical inversion solution for processing lidar returns. Appl. Optics, 20, 211-220, doi: 10.1364/AO.20.000211. [Link]

Liu, X., H. M. Tulldahl, and A. Axelsson, 2010: Bathymetry LiDAR reflectance processing and seafloor classification. Proceeding of European LiDAR Mapping Forum, Netherlands, 30 Nov. - 1 Dec., 2010.

Lundblad, E. R., D. J. Wright, J. Miller, E. M. Larkin, R. Rinehart, D. F. Naar, B. T. Donahue, S. M. Anderson, and T. Battista, 2006: A benthic terrain classification scheme for American Samoa. Mar. Geodesy, 29, 89111, doi: 10.1080/01490410600738021. [Link]

Lyzenga, D. R., 1981: Remote sensing of bottom reflectance and water attenuation parameters in shallow water using aircraft and Landsat data. Int. J. Remote Sens., 2, 71-82, doi: 10.1080/01431168108948342. [Link]

Micallef, A., T. P. Le Bas, V. A. I. Huvenne, P. Blondel, V. Hühnerbach, and A. Deidun, 2012: A multi-method approach for benthic habitat mapping of shallow coastal areas with high-resolution multibeam data. Cont. Shelf Res., 39-40, 14-26, doi: 10.1016/j.csr.2012.03.008. [Link]

Phillips, D. M., R. H. Abbot, and M. F. Penny, 1984: Remote sensing of sea water turbidity with an airborne laser system. J. Phys. D: Appl. Phys., 17, 1749-1758, doi: 10.1088/0022-3727/17/8/028. [Link]

Shih, P. T. Y., D. Arumugam, and S. W. Shyue, 2011: Bathymetric lidar survey of Penghu Islands and Dongsha Atoll: Using an ellipsoidal height system for bathymetric mapping in shallow waters and difficult-to-navigate environments. Sea Tech., 52, 42-45.

Steinvall, O. K. and K. R. Koppari, 1996: Depth sounding lidar: An overview of Swedish activities and future prospects. Proc. SPIE, 2964, 2-25, doi: 10.1117/12.258342. [Link]

Steinvall, O. K., K. R. Koppari, and U. C. M. Karlsson, 1994: Airborne laser depth sounding: System aspects and performance. Proc. SPIE, 2258, 392-412, doi: 10.1117/12.190082. [Link]

Stumpf, R.P., K. Holderied, and M. Sinclair, 2003: Determination of water depth with high-resolution satellite imagery over variable bottom types. Limnol. Oceanogr., 48, 547-556, doi: 10.4319/lo.2003.48.1_part_2.0547. [Link]

Tulldahl, H. M. and K. O. Steinvall, 2004: Simulation of sea surface wave influence on small target detection with airborne laser depth sounding. Appl. Optics, 43, 
2462-2483, doi: 10.1364/AO.43.002462. [Link]

Tulldahl, H. M. and S. A. Wikström, 2012: Classification of aquatic macrovegetation and substrates with airborne lidar. Remote Sens. Environ., 121, 347-357, doi: 10.1016/j.rse.2012.02.004. [Link]

Wang, C. K. and W. D. Philpot, 2007: Using airborne bathymetric LiDAR to detect bottom type variation in shallow waters. Remote Sens. Environ., 106, 123-135, doi: 10.1016/j.rse.2006.08.003. [Link]

Wedding, L. M., A. M. Friedlander, M. McGranaghan, R.
S. Yost, and M. E. Monaco, 2008: Using bathymetric lidar to define nearshore benthic habitat complexity: Implications for management of reef fish assemblages in Hawaii. Remote Sens. Environ., 112, 4159-4165, doi: 10.1016/j.rse.2008.01.025. [Link]

Wilson, M. F. J., B. O’Connell, C. Brown, J. C. Guinan, and A. J. Grehan, 2007: Multiscale terrain analysis of multibeam bathymetry data for habitat mapping on the continental slope. Mar. Geodesy, 30, 3-35, doi: 10.1080/01490410701295962. [Link] 